\title{
Alfabetização semiótica com os códigos informático-digitais da internet
}

Irene de Araujo Machado

Liure-docente em Ciências da Comunicação pela Escola de Comunicações e Artes (ECA) da Universidade de São Paulo (USP). Atualmente é professora associada da ECA/USP e do Programa de Pós-Graduação em Meios e Processos Audiovisuais.

E-mail: irenear@usp.br

\section{Daniela Osvald Ramos}

Jornalista, professora da graduação em Educomunicação e no Programa de Pós-Graduação em Ciências da Comunicação da Escola de Comunicações e Artes da Universidade de São Paulo.

E-mail:dramos@usp.br

Resumo: Neste artigo, abordamos as mudanças sociotécnicas na contemporaneidade a partir de uma abordagem histórica advinda da introdução da internet na cultura. Posteriormente, investigamos a importância do conhecimento dos códigos informático-digitais neste contexto. Desenvolvemos a hipótese de que é necessário enfrentar a complexidade do entendimento da infraestrutura técnica da rede para que possamos formar cidadãos, e não usuários que consomem toda sorte de códigos a partir de dinâmicas complexas e constantes de codificação e recodificação, sem a competência semiótica adequada para a interpretação crítica a partir da autorreferencialidade que a linguagem nos impõe neste novo quadro histórico. Concluímos que é necessário um projeto de alfabetização que contemple o entendimento do uso dos códigos na comunicação.

Palavraschave: alfabetização semiótica; códigos informáticos; internet; tecnocultura; autorreferencialidade.
Abstract: In this article, we address the socio-technical changes in contemporary times by a historical approach arising from the introduction of internet in the culture. Subsequently, we investigated the importance of knowledge of digital codes in this context. We formulated the hypothesis that it is necessary to face the complexity of understanding the technical infrastructure of the network so that we can educate citizens, and not users, who consume all sorts of codes from complex and constant coding and recoding dynamics, without the proper semiotic competence for the critical interpretation based on the self-referentiality that language imposes on us in this new historical framework. As a conclusion, we assume that there is a need for a literacy project that includes the understanding of the use of codes in communication.

Keywords: semiotic literacy; digital codes; internet; technoculture; self-referentiality. 


\section{INTRODUÇÃO}

O desenvolvimento técnico da internet remonta ao contexto da Guerra Fria, entre Estados Unidos e a então União Soviética, após a Segunda Guerra Mundial, no Departamento de Defesa norte-americano, e à consequente criação da Arpanet, seu primeiro protótipo. Esta história envolve muitos engenheiros que planejaram tanto as estruturas de rede e seus funcionamentos como todo o hardware que dá suporte à existência da internet. Logo depois, nos anos 1960, Marshall McLuhan já anunciava a aldeia global, enquanto Stewart Brand ia para a prática com o Whole Earth Catalogue. Este projeto, que durou de 1968 a 1972, era uma revista de contracultura que, além de promover a venda ou troca de produtos, pregava o DIY (do it yourself, do inglês, faça você mesmo) e acesso pleno às ferramentas, algo que se realizou com a expansão da internet nos anos 1990, justamente pela facilidade de circulação e acesso a toda sorte de informação e tutoriais, ou how to do's. O Whole Earth Catalogue hoje tem nome e endereço web: é o Google, portal de acesso aos conteúdos acessíveis em uma primeira camada de busca na rede ${ }^{1}$.

Depois da construção da infraestrutura e da popularização do acesso, a internet começou a se expandir no mundo inteiro na última década do século XX. Em 1995 iniciaram suas atividades comerciais no Brasil, ou seja, a venda de acesso e, claro, o começo do desenvolvimento de novos modelos de negócio para a rede que, posteriormente, acabariam com os outros previamente estabelecidos, como foi notoriamente o caso da indústria fonográfica e do jornalismo, para citarmos dois exemplos amplamente conhecidos. Sem dúvida, estas mudanças alteraram várias dinâmicas sociais que até então definiam práticas econômicas, políticas, culturais e educacionais. Seu centro é a desintermediação a partir dos intermediários até então conhecidos - como empresas, políticos, jornalistas, professores -, pela intermediação única através de um centro de cálculo operado por humanos e que funciona em rede.

Galloway ${ }^{2}$ detalha este processo, e Eugene Thacker ${ }^{3}$, prefaciando Galloway, analisa que este controle se dá na forma contemporânea de operar a biopolítica, o controle sobre os corpos, conceito elaborado por Michel Foucault ${ }^{4}$. O biopoder advindo da internet se organiza como controle em protocolos literais, pois se trata da infraestrutura física de gerenciamento de rede. Assim, o controle advém agora de um único sistema e tem a característica de ser um diagrama, tecnologia e estilo de gerenciamento. Nas palavras de Thacker,

it is worthwhile to note that the concept of "protocol" is related to a biopolitical production, a production of the possibility for experience in control societies. It is in this sense that Protocol is doubly materialist-in the sense of networked bodies inscribed by informatics, and in the sense of this bio-informatic network producing the conditions of experience ${ }^{5}$.

Assim, para que o controle operado por humanos aconteça na internet, é preciso codificar filtros de vários tipos que funcionam, por sua vez, como protocolos de distribuição dos dados, que se convertem em conteúdo que pode
1. WIENER, Anna. The complicated legacy of Stewart Brand's "Whole Earth Catalog". The New Yorker, New York, 16 nov. 2018. Letter from Silicon Valley. Disponível em: https://www.newyorker.com/news/letterfrom-silicon-valley/thecomplicated-legacy-ofstewart-brands-wholeearth-catalog. Acesso em: 15 nov. 2019.

2. GALLOWAY, Alexander. Protocol: how control exists after decentralization. Massachusetts: The MIT Press, 2004.

3. THACKER, Eugene. Foreword: protocol is as protocol does. In: GALLOWAY, op. cit., p. XIXXIV.

4. FOUCAULT, Michel. Nascimento da biopolítica. Lisboa: Edições 70, 2010.

5. THACKER, op. cit., p. XIX-XX. Em tradução livre das autoras, "vale a pena notar que o conceito de 'protocolo' está relacionado a uma produção biopolítica, uma produção da possibilidade de experiência em sociedades de controle. É nesse sentido que o Protocolo é duplamente materialista no sentido de corpos em rede inscritos pela informática, e no sentido desta rede bioinformática que produz as condições de experiência". 
ser consumido. Estes protocolos são constituídos por códigos informático-digitais. Temos alguns níveis de protocolos, assim como podemos ter vários níveis de códigos informático-digitais. Existem os protocolos que controlam a infraestrutura física da internet, e outros que funciona através de proxies. O proxy age também como intermediário de distribuição de protocolos e pode ser transparente, altamente anônimo, mais difícil de ser rastreado, ou apenas anônimo, com alguma proteção ${ }^{6}$.

No estágio inicial da internet, no início dos anos 1990, estar na rede tinha um caráter lúdico primordial, de descoberta, jogo e anonimato. Isso se manifestava no então hábito de entrar na rede sempre com um avatar, que significa adotar uma identidade cibernética, ou então, mais simplesmente, adotar um nickname, um apelido. Tal contexto, que talvez se deva ao conhecimento então mais difundido da arquitetura de rede e das possibilidades de transparência total e sua regulação através de recursos para manter certo anonimato, se modificou radicalmente a partir da expansão da internet como um novo espaço de transação comercial. Assim, tornou-se necessário que todos se identificassem civilmente na rede, de forma que os dados de navegação e preferências poderiam ser associados sem dúvida à identidade civil e a números de registro de navegação que consolidam os dados de consumo tanto objetivo, as compras de produtos, quanto subjetivo, ou seja, as preferências de gosto.

Depois de 25 anos de operação comercial no Brasil, pode-se dizer que usar a internet é fácil. Mas não foi assim desde o princípio, quando era preciso primeiro dominar os códigos de acesso do sistema operacional DOS, da Microsoft, para entrar no computador e na internet (Figura 1), que ainda não era a World Wide Web (WWW), interface gráfica criada posteriormente por Tim BernersLee, no ano referência de 1989, segundo a Wikipédia 7 .

6. PÉREZ, Ignacio. El rol de los proxies y protocolos en la investigación de malware. We live security, Buenos Aires, 29 maio 2015. Disponível em: https:// www.welivesecurity.com/ la-es/2015/05/29/proxies-y-protocolos-investigacion-malware/. Acesso em: 15 nov. 2019.

7. TIM Berners-Lee. In: WIKIPÉDIA: a enciclopédia livre. [San Francisco, CA: Wikimedia Foundation, 20-]. Disponível em: https:// pt.wikipedia.org/wiki/Tim_ Berners-Lee. Acesso em: 20 nov. 2019.

8. Disponível em: https:// pt.wikipedia.org/wiki/Bulletin_board_system\#/media/ Ficheiro:Monochrome-bbs. png. Acesso em: 9 jan. 2020.

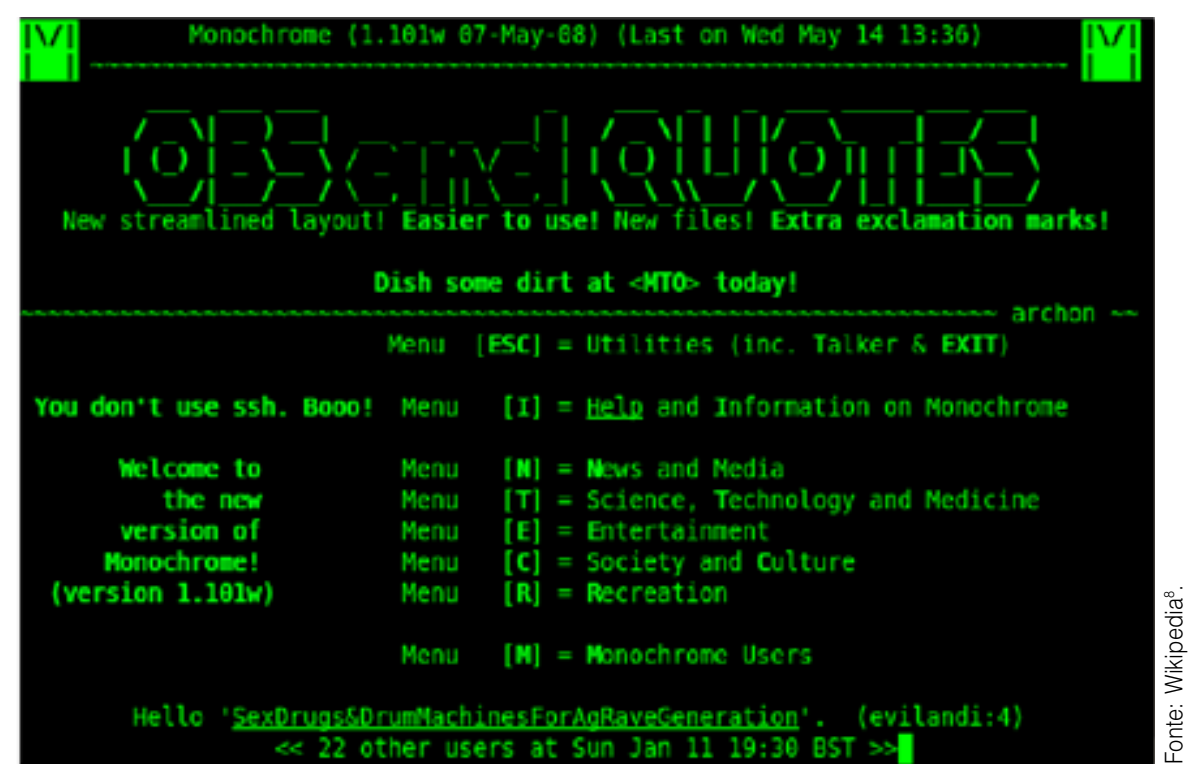

Figura 1: Interface da internet antes da popularização da WWW 
Passados no mínimo 40 anos desde este contexto inicial, ao final da primeira década do século XXI, percebe-se que além do esquecimento coletivo sobre o caminho que nos levou até aqui, como a natureza eminentemente técnica da rede e as ideologias de seu projeto técnico, a melhoria das interfaces gráficas cobriu quase totalmente a camada que era mais perceptível na Figura 1: o uso dos códigos informático-digitais, que ocorre em diversos níveis. Por sua vez, estes códigos são direcionados por meios dos proxies e protocolos de rede que, por sua vez, também são codificados. Diversas ordens de códigos informático-digitais modelizam ${ }^{9}$ tudo que atravessa os cabos de fibra ótica e alcança os computadores que servem de acesso à internet. São processos constantes de codificação, decodificação e transcodificação. Manovich sugere a seguinte hierarquia de níveis: "interface-conteúdo; sistema operacional-aplicação; página web-código HTML; linguagem de programação de alto nível-linguagem assembly $^{10}$-linguagem de máquina"11. O que podemos observar neste caso é a necessidade constante de recodificação, enquanto a decodificação é mascarada para o usuário final e só pode ser dada a ver por quem conhece e entende estas diversas ordens de codificação e recodificação.

Como evidência destas necessidades técnicas de recodificação, o símbolo escolhido para o navegador anônimo do Projeto TOR é uma cebola (Figura 2), e foi a metáfora escolhida pela própria comunidade de programadores que desenvolveu esta ferramenta, ilustrando a possibilidade de entrar na internet com o entendimento de que este ambiente é composto por várias camadas de código, como uma cebola. O TOR vai "descascando" cada camada de código, sem deixar rastro. Atravessa proxies e protocolos embaralhando números, de modo a não ser rastreável. Esta é uma mudança sociotécnica profunda e pouco conhecida socialmente, pela sua alta especificidade e complexidade. No entanto, percebemos seus efeitos sociais quando fenômenos complexos emergem desta camada anônima da internet.

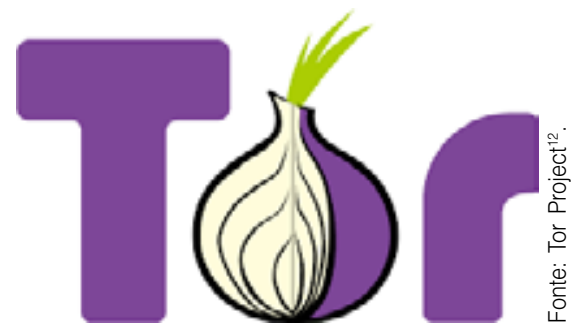

Figura 2: Logotipo do Projeto TOR, que oferece um navegador que torna possível a navegação anônima na internet

Este projeto de anonimato é também um manifesto:

In the 1990s, the lack of security on the internet and its ability to be used for tracking and surveillance was becoming clear, and in 1995, David Goldschlag, Mike Reed, and Paul Syverson at the U.S. Naval Research Lab (NRL) asked themselves if there was a way to create internet connections that don't reveal who is talking to whom, even to someone monitoring the network. Their
9. O conceito de modelização foi proposto por Lotman para entender como os códigos se relacionam em diferentes linguagens de um sistema semiótico de modo a organizar os textos da cultura. LOTMAN, luri. A estrutura do texto artístico. Lisboa: Estampa, 1978, p. 16.

10. "Assembly ou linguagem de montagem é uma notação legível por humanos para o código de máquina que uma arquitetura de computador específica usa". LINGUAGEM assembly. In: WIKIPÉDIA: a enciclopédia livre. [San Francisco, CA: Wikimedia Foundation, 2016]. Disponível em: http://pt.wikipedia. org/wiki/Assembly. Acesso em: 25 out. 2010.

11. MANOVICH, Lev. Database as symbolic form. Convergence, Thousand Oaks, v. 5, n. 2, p. 81-99, 1999, p. 97, tradução nossa. Destacamos que a linguagem de alto nível é capaz de realizar operações mais refinadas e abstratas, como as previstas nos softwares, e que a linguagem Assembly está relacionada com a linguagem da máquina (também chamada de baixo nível).

12. Disponível em: https:// www.torproject.org/. Acesso em: 27 dez. 2019. 
13. HISTORY. In: TOR Project. Seattle: The Tor Project, 2011. Disponível em: https://www.torproject.org/ about/history/. Acesso em: 27 dez. 2019. Tradução livre das autoras: "Na década de 1990, a falta de segurança na internet e sua capacidade de ser usada para rastreamento e vigilância estavam se tornando claras e, em 1995, David Goldschlag Mike Reed e Paul Syverson, do Laboratório de Pesquisa Naval dos EUA (NRL), se perguntaram se havia uma maneira de criar conexões com a internet que não revelassem quem está falando com quem, nem mesmo para quem monitorasse a rede. Sua resposta foi criar e implementar os primeiros projetos de pesquisa e o protótipo de roteamento de cebola. O objetivo do roteamento de cebola era ter uma maneira de usar a internet com o máximo de privacidade possível, e a ideia era rotear o tráfego através de vários servidores e criptografá-lo a cada passo do caminho. Essa ainda é uma explicação simples de como o Tor funciona hoje."

14. HERN, Alex. Revealed: how TikTok censors videos that do not please Beijing. The Guardian, London, 25 set. 2019. Disponível em: https://www.theguardian com/technology/2019/ sep/25/revealed-how-tiktok-censors-videos-thatdo-not-please-beijing. Acesso em: 14 out. 2019. answer was to create and deploy the first research designs and prototypes of onion routing.

The goal of onion routing was to have a way to use the internet with as much privacy as possible, and the idea was to route traffic through multiple servers and encrypt it each step of the way. This is still a simple explanation for how Tor works today ${ }^{13}$.

Podemos dizer, então, que entender a mediação técnica que ocorre no consumo de informação pela internet é fundamental. Esta mediação se desenvolve em um constante aprimoramento dos códigos nestes diversos níveis, sejam os códigos de máquina, que permitem que os hardwares processem de forma cada vez mais rápida, sejam os de software, com o aperfeiçoamento dos algoritmos e suas funções. Quem domina os códigos domina o processo de circulação. Esta dominação, no sentido estrito da palavra, ou seja, de controle, é também fragmentada. Alguns dominam os códigos em nível de máquina, outros de software, outros, ainda, os códigos da circulação de conteúdo em determinados formatos, como os formatos de busca, cujo maior representante é o Google, que domina seus próprios códigos, já que são propriedade privada. Assim, aqueles que dominam os códigos passam a controlar o acesso a conteúdos e ainda, mais do que o acesso, a forma como este se dá.

Quem controla totalmente os códigos? Talvez nunca saberemos ao certo, mas sabemos que potencialmente este controle é de quem tem o conhecimento necessário tanto para elaborar novos códigos quanto para quebrar os códigos proprietários. Estes indivíduos podem atuar em empresas ou de forma independente, como hackers ou crackers, aqueles que quebram códigos porque ou querem entender como funcionam, ou têm algum objetivo escuso. Quando a quebra dos códigos beira o impossível, é necessário entender a sua dinâmica para então manipulá-los indiretamente. Isso aconteceu, por exemplo, no caso das eleições norte-americanas, quando a Cambridge Analytica comprou os dados e metadados de usuários e pôde elaborar um código algoritmizado para o processamento destes dados visando certos efeitos cognitivos baseados em análises psicométricas calculadas para atingir determinados efeitos, leia-se: para influenciar o voto em determinado candidato.

Desta forma, os códigos de diversas ordens criam um novo modelo de negócio que é também a dinâmica de consumo de conteúdo contemporânea, tal como podemos visualizar no Quadro 1.

Nestes níveis, se dá de forma contínua o aprimoramento da mediação do código, cada vez mais eficiente do ponto de vista do seu processamento pela máquina. O problema de dominação dos códigos atinge contemporaneamente uma dimensão geopolítica. Um recente aplicativo chinês de consumo de vídeos, o TikTok, alcançou grande sucesso nos Estados Unidos em $2019^{14}$. Cada pessoa pode facilmente gravar e postar um vídeo no aplicativo e categorizá-lo de acordo com uma hashtag. Este termo é usado para designar uma ou mais palavras-chave precedidas pelo símbolo \#, que servem à 
organização de conteúdos em diversas plataformas, como o Twitter, uma das primeiras a utilizá-lo de forma coletiva.

Assim, se realizo um evento, por exemplo, e quero divulgá-lo na internet de forma descentralizada, designo uma hashtag para ele, como "\#evento2019". A partir da utilização desta hashtag em todas as fotos, textos, vídeos, posso recuperar o conteúdo de diferentes pessoas sobre o mesmo tema. Shirky ${ }^{15}$ utilizou a expressão "organizar sem organizações" para descrever este fenômeno. É com esta dinâmica que o TikTok funciona. Porém, nota-se que dentro do aplicativo não circulam temas sensíveis ao governo chinês, como o uso das palavras-chave Tiananmen Square ou Tibetan Independence, e também não há nada de vídeos dos protestos em Honk Kong, que ocorreram intensivamente desde junho de 2019. O aplicativo tem 500 milhões de usuários no mundo inteiro e preocupa o Ocidente por poder estar moldando a percepção de mundo destas pessoas com base no que os chineses entendem sobre "o que é o mundo", exercendo uma moderação censória de conteúdos ou, podemos dizer, uma ação humana deliberada sobre os códigos ${ }^{16}$, exercitando o controle a partir de um estilo de gerenciamento ${ }^{17}$.

\section{Quadro 1: Níveis possíveis de codificação na dinâmica de extração e processamento de dados}

\begin{tabular}{|l|l|}
\hline 1. Extração de dados & $\begin{array}{l}\text { Treinar a sociedade para extração de seus dados } \\
\text { de diversas ordens, individuais e/ou de associação } \\
\text { coletiva, e naturalização deste processo. }\end{array}$ \\
\hline $\begin{array}{l}\text { 2. Transformar dados em metadados } \\
\text { 3. Processar com algoritmos }\end{array}$ & $\begin{array}{l}\text { A partir dos dados coletados, gerar metadados } \\
\text { possíveis. }\end{array}$ \\
\hline $\begin{array}{l}\text { 4. Orientar para o consumo objetivo/ } \\
\text { subjetivo }\end{array}$ & $\begin{array}{l}\text { Mapear padrões de consumo objetivo e subjetivo; } \\
\text { cruzar estes padrões com a "média" do Big Data. } \\
\text { também mediação dos processos sociais como um } \\
\text { todo (triagens, policiamento, educação, segurança } \\
\text { pública etc.). }\end{array}$ \\
\hline $\begin{array}{l}\text { 5. Reforças padrões; gerar novos } \\
\text { padrões }\end{array}$ & $\begin{array}{l}\text { Padrões de preferências de consumo individual } \\
\text { passam a ser reforçados. } \\
\text { Padrões de inclusão e/ou exclusão social também } \\
\text { podem ser reforçados. }\end{array}$ \\
\hline
\end{tabular}

Fonte: elaborado pelos autores.

15. SHIRKY, Clay. Lá vem todo mundo: o poder de organizar sem organizações. Rio de Janeiro: Zahar, 2011.

16. HERN, op. cit. 17. THACKER, op. cit. 
comunicação \& educação • Ano XXIV • número 2 • jul/dez 2019

18. VOLLI, Ugo. Factoides y mnemos: por una ecología semiótica. In: TALENS, Jenaro (dir.). Videoculturas de fin de siglo. Madrid: Cátedra, 1990, p. 129-135.

19. COLOMBO, Fausto. El ícono ético: la imagen de sínteses y un nuevo paradigma moral. In: TALENS, Jenaro (dir.). Videoculturas de fin de siglo. Madrid: Cátedra, 1990, p. 145-156.

20. LOTMAN, Juri. The unpredictable workings of culture. Tallinn: Tallinn University Press, 2013; PRIGOGINE, llya; STENGERS, Isabelle. A nova aliança. Brasília, DF: Editora UnB 1997.

21. HOFSTADTER, Douglas. Godel, Escher, Bach: an eternal golden braid. New York: Basic Books, 1979.

22. JAKOBSON, Roman. Linguística e poética. In: JAKOBSON, Roman. Linguística e comunicação. São Paulo: Cultrix, 1971. p. 118-162.

23. MATURANA, Humberto. Emociones y lenguaje en educación y política. Santiago: Dolmen, 1997; MATURANA, Humberto: VARELA, Francisco. A árvore do conhecimento: as bases biológicas do entendimento humano. Campinas: Psy, 1995

24. O poeta francês Paul Valéry dedicou ao mito do Ouroboros um de seus mais ousados poemas: Ébauche d'Un Serpent (Esboço para uma serpente), traduzido para o português pelo poeta brasileiro Augusto de Campos. CAMPOS, Augusto de. Paul Valéry: a serpente e o pensar. São Paulo: Brasiliense, 1984.

\section{ASSOMBROS DA AUTORREFERENCIALIDADE EM APONTAMENTOS CRÍTICOS}

A relação entre dominação e controle dos códigos informático-digitais parece ter criado uma estratégia de uso de caráter determinista, certeiro e inabalável, seja quando se refere à impossibilidade de rastreamento ou quando mapeada pelas esferas de controle geopoliticamente configuradas. Tornados usuários, os cidadãos que carecem não apenas de poder aquisitivo, mas também de inteligência para ter acesso real aos privilégios dos sistemas informático-digitais, parecem perder a capacidade de reflexão crítica.

Se existe uma característica fundamental aos estudos de teoria da comunicação, trata-se do desenvolvimento da compreensão crítica dos meios, seus códigos e linguagens, no âmbito de sua historicidade, de modo a alcançar suas dimensões socioculturais que excedem a materialidade técnica. Logo, é chegada a hora de enfrentarmos a dimensão da crítica dos meios potencializando o que se afirmou até aqui sobre o papel e o poder dos códigos das mídias informático-digitais. Para isso, há que se enfatizar a abordagem dos usos sociais, deslocando o foco da eficiência e previsibilidade para a imprevisibilidade da produção de significados no vasto campo da "ecologia semiótica"18 e do paradigma moral que os signos icônicos instauraram em termos éticos ${ }^{19}$.

Sem perder de vista que o determinismo protocolar sustenta a mobilidade e eficiência dos sistemas informáticos no tratamento de dados, interessa debater a noção segundo a qual tais procedimentos marcam uma mudança sociotécnica profunda e pouco conhecida socialmente, como se afirmou anteriormente, devido à alta especificidade e complexidade. Considerando que o estudo dos sistemas de grande complexidade, da emergência e até mesmo da quebra de códigos são contemporâneos de conquistas científicas do pós-guerra, ganha evidência que os avanços no entendimento dos sistemas entrópicos no contexto da segunda lei da termodinâmica introduzem noções de indeterminismo, incerteza e imprevisibilidade ${ }^{20}$, abrindo possibilidades para investigações críticas no interior das novas realidades sociotécnicas. Um fenômeno particular dos processos sociotécnicos merece atenção: o fenômeno que o cientista cognitivista Douglas Richard Hofstadter ${ }^{21}$ denominou como "autorreferencialidade".

Autorreferencialidade designa todos os processos de recursão, onde quer que eles aconteçam. Na computação, designa a operatividade de programas que mobilizam seus próprios constituintes para realizar cálculos, tal como o processo randômico numérico. Na linguagem, a função metalinguística ${ }^{22}$ volta-se sobre si mesma para produzir significados. Na biologia, entende-se por autorreferência o desenvolvimento celular em que a própria célula se regenera num processo de autopoiese ${ }^{23}$. Na literatura e nas artes, a autorreflexividade questiona procedimentos em favor da criatividade e da crítica dos meios e processos de produção de sentido. Em todos estes campos ressoa a presença de um dos símbolos ancestrais da autorreferência: o Ouroboros, a serpente/ dragão que come a própria cauda ${ }^{24}$. 


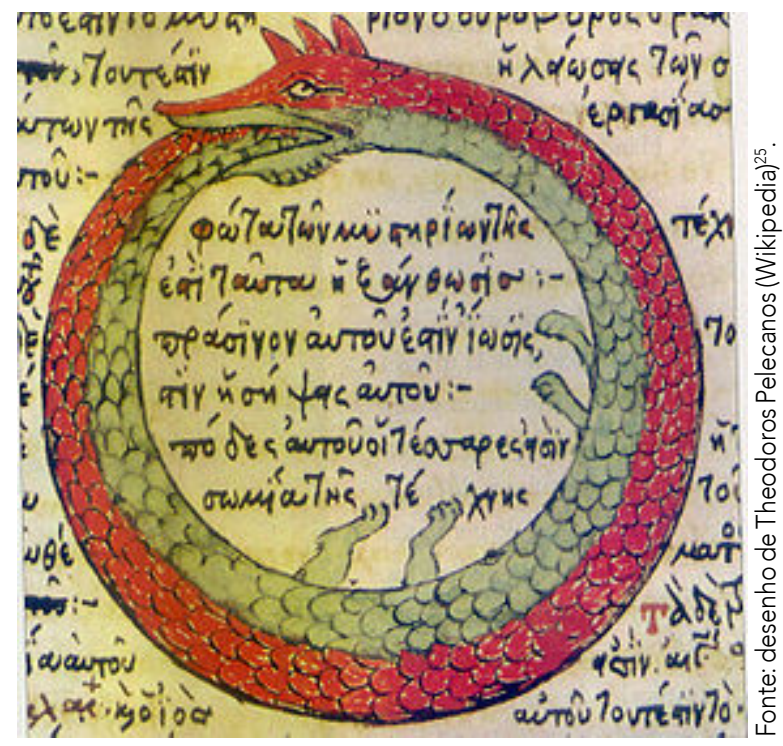

Figura 3: Ouroboros

À luz da autorreferencialidade, pode-se inferir que nenhum entendimento pode prescindir de estudos sobre seus próprios meios de produção, o que sustenta a demanda de examinar as relações socioculturais segundo um viés da crítica dos meios em sua história e historicidade, o que equivale a focalizar os códigos informático-digitais na linhagem do desenvolvimento histórico dos demais códigos culturais. De saída, há pressupostos a serem observados: (1) a racionalidade técnica não é privilégio da elaboração dos códigos informático-digitais, mas do desenvolvimento da técnica, como nos lembra Walter Benjaminn ${ }^{26}$; (2) os códigos são convenções criadas socialmente em diferentes campos do saber; (3) o controle dos códigos não surge com a internet; e (4) a tecnocultura informática integra o processo de cibernetização da cultura instaurado no bojo de muitas descobertas científicas. Se pensado no contracampo dos fenômenos da autorreferencialidade em que os sistemas sociais, humanos, revelam-se sistemas de altíssima complexidade, fora do alcance de qualquer equiparação,o problema da dominação e do controle certeiro não se coloca como obstáculo epistemológico intransponível, como o campo de forças e de disputas técnicas nos faz crer. Ocorrências atuais em circulação abrem caminho para se pensar nos limites em que certezas escapam aos padrões tão rigidamente programados.

Campanhas educativas transmitidas pelo rádio - o meio ainda mais eficiente para atingir os polos mais distantes e de difícil acesso no país - são enunciadas como um sinal de alerta às mensagens duvidosas que circulam pelas redes sociais das mídias móveis ao longo dos últimos anos (2018-2019). O alerta declara: "essa é uma mensagem [ou notícia] falsa". Não é preciso muita teoria para perceber que a frase enunciada consiste em um paradoxo: a frase está correta, contudo, a relação com sua referência não: uma mensagem (notícia) só pode ser verdadeira; se for falsa, não é mensagem. Estamos diante das

25. Disponivel em: https://en.wikipedia.org/ wiki/Ouroboros\#/media/ File:Serpiente_alquimica. jpg. Acesso em: 9 jan. 2020.

26. BENJAMIN, Walter. A obra de arte na era de sua reprodutibilidade técnica. A obra de arte na era de sua reprodutibilidade técnica. In: BENAJMIN, Walter. Sobre arte, técnica e política. Lisboa: Relógio D’Água, 1992. p. 71113. 
27. COLOMBO, op. cit.

28. VOLLI, op. cit.

29. MORIN, Edgar. O ano zero da Alemanha. Porto Alegre: Sulina, 2009.

30. O sufixo "oide" acrescenta um significado depreciativo à palavra (tal como em "debiloide", "intelectualoide", "humanoide" etc.). VOLLI, op. cit.

31. Informação e informática designam entidades distintas. Como nos esclarece Gianfranco Bettetini, "informação se refere à determinação do que é determinável: um determinável que, na tradição aristotélica, está representado pela matéria e que, na perspectiva lógica de quantificação da informática, se reduz a uma relação de alternativa binária que supõe uma decisão de escolher entre duas possibilidades". Informação significa, pois, quantidades; informática, cálculos de operações matemáticas. BETTETINI, Gianfranco. Las ambigüedades del sujeto informador. BETTETINI, Gianfranco. La conversación audiovisual. Madrid: Cátedra, 1996, p. 63.

32. YOUNGBLOOD apud COLOMBO, op. cit. p. 156. mazelas de um enunciado inquietante, autorreferencial. Significação autorreferencial tem sido objeto de estudo privilegiado de disciplinas linguísticas e deveria sê-lo de todas as ciências que gravitam em torno da linguagem, colocando em risco e desafiando a referencialidade do signo ${ }^{27}$.

O debate contemporâneo que afeta e assombra diferentes campos da reflexão teórica gravita em torno de um problema de autorreferencialidade: as fake news que, num passado não muito distante, eram entendidas como "factoides" 28 ou, ainda, como "rumores", em documentação de Morin ${ }^{29}$ sobre o pós-segunda guerra mundial, a respeito dos boatos de que Hitler ainda estaria vivo. Ainda que seja produção da comunicação em rede de telefonia móvel e internet, assim como as fake news, o factoide ${ }^{30}$ surge como um neologismo no contexto da geopolítica da língua inglesa estadunidense quando da expansão da imprensa e do media power na era da comunicação de massa; não é produto, pois, da internet.

Não obstante a crise esteja instalada e, cada vez mais, ameace o universo de sentidos nas produções comunicacionais, a autorreferencialidade e todo o campo conceitual do ruído, entropia, simulacros, autopoiese, controle e segunda lei da termodinâmica continuam sendo objetos do interesse dos físicos, dos engenheiros e dos teóricos da informação, informática, cibernética, mas não dos teóricos da comunicação e da linguagem. Temos aqui um real obstáculo epistemológico a impedir conquistas de conhecimento.

Os assombros que nos afetam nos levam a desconfiar de tais preceitos, afinal, não há como duvidar dos ruídos sintéticos que nos afrontam nesses tempos sombrios, colocando em risco aquilo que define nossa condição cultural-antropológica: a interação humana e a autonomia de produção de discursos. Os meios digitais em suas redes telemáticas e informáticas de informação ${ }^{31}$ mudaram a ecologia dos sistemas comunicacionais, colocando em evidência os agentes da racionalidade técnica e o campo de forças que se esparramam irreversivelmente pelas relações sociotécnicas.

Sem desdenhar das ameaças, nossa arma continua sendo o pensamento traduzido em signos das linguagens da comunicação. Logo, não há por que não enfrentar os desafios recorrendo às teorias que, queiramos ou não, examinam conceitos pertinentes ao mundo da comunicação, tal como colocado na primeira parte deste artigo. Este é o principal objetivo de nossa contribuição ao debate contemporâneo em pauta que pode, sem dúvida, abrir caminhos explicativos por entre seus ruídos sintéticos de factoides, fake news, memes e todos estes movimentos entrópicos do mundo não determinista.

No afã de construção de um mundo sintético, baseado no cálculo numérico e em combinatórias de possibilidades infinitas, os processos autorreferenciais resultam diretamente do trabalho de códigos da linguagem informática. O núcleo duro do sistema informático depende, pois, de algoritmos, não de referentes analógicos. Trata-se de "um autêntico produto da simulação"32.

Sabemos que sem código nenhuma linguagem e nenhuma cultura se sustentam. A civilização ocidental teve seu desenvolvimento marcado pela descoberta do alfabeto e a consequente invenção da escrita, que se tornou a força multiplicadora 
de códigos. Como entender o mundo audiovisual em que vivemos sem compreender a dinâmica dos códigos fotográficos da luz produtores de imagens que dominam os ambientes culturais? O mesmo se pode dizer dos códigos informático-digitais. Contudo, os códigos são convenções culturais frutos de conquistas intelectuais.

Do ponto de vista histórico, o surgimento da escrita colocou como desafio não apenas o aprendizado de um código, mas também o desenvolvimento de habilidades cognitivas para sua leitura. Para os historiadores da cultura, a grande invenção da escrita não se concentra na aquisição do código alfabético, mas sim no surgimento do homem leitor. O homem leitor é o agente da leitura, e esta é a grande força que desencadeou o exponencial evento civilizatório na magnitude de sua expansão em constante devir. Frutos de tal empreendimento, só podemos lastimar que a tão proclamada cultura digital até agora não parece disposta a potencializar nenhuma capacidade humana, uma vez que o leitor foi relegado à mera condição de usuário. Somos apenas consumidores de um mercado de consumo, ignorantes analfabetos das mídias digitais. Podemos dizer que, sob este ponto de vista, o modelo de negócio implantado pela internet foi bem-sucedido, já que chances de leitura crítica diminuem drasticamente se não enfrentarmos a diferença entre a formação de cidadãos e usuários.

Assim, se coloca à nossa frente o grande paradoxo dos códigos autorreferenciais do ambiente virtual digital: o radical distanciamento entre a mão nossos dígitos - e o nosso cérebro. Não foi a conexão entre mão e córtex cerebral que condicionou a distinção entre homem e símio, capacitando nossos ancestrais a se manterem em pé, libertando as mãos para realizar tarefas ${ }^{33}$. Estaríamos condenados à ignorância daqueles que apenas surfam nas ondas da superficialidade das redes digitais se não fosse a possibilidade de compreender o funcionamento dos códigos digitais, de sua capacidade gerativa de simular mundos virtuais e do desenvolvimento de linguagens artificiais que movimentam informações e comunicação. Concentremo-nos no entendimento dos códigos e dos ambientes que eles desenvolvem.

Aprendemos com M. McLuhan ${ }^{34}$ que os meios geram ambientes, uma vez que conjugam diferentes modos de processar a informação disponível e torná-la acessível à percepção, cognição e interação humana. Assim entendia o meio de comunicação: aquele que age por mediações ambientais. Para McLuhan, um ambiente assim constituído movimentava um processo de cibernetização da comunicação e da cultura, visto que o processamento de informação disponível nos ambientes conjugava ações de diferentes fontes, a saber, ambiental, humana e maquínica, o que demanda um exercício de controle em luta contra a entropia. Em consequência, para compreender a natureza e a ação dos meios, há que se situar a informação no centro do universo comunicativo. Tal entendimento não foi levado a sério, para o azar das gerações futuras que no século 21 nascem, crescem e vivem em conexões de redes em ambientes virtuais - de simulação em redes autorreferenciais sujeitas a todo tipo de entropia.

Umberto Eco teve mais sorte: tornou-se um semioticista respeitado cuja ousadia o levou a avançar muitas das propostas anunciadas pelo guru canadense. Em um
33. ENGELS, Friedrich Humanização do macaco pelo trabalho. In: ENGELS, Friedrich. A dialética da natureza. Rio de Janeiro: Paz e Terra, 1979. p. 215-217. 34. MCLUHAN, Marshall; FIORE, Quentin. O meio são as massagens: um inventário de efeitos. Rio de Janeiro: Record, 1969. 
35. ECO, Umberto. Guerrilha semiológica. In: ECO, Umberto. Viagem na irrealidade cotidiana. Rio de Janeiro: Nova Fronteira, 1984. p. 165-175.

36. Ibidem, p. 168.

37. Ibidem, p. 171.

38. Ibidem, p. 172.

39. DOG-whistle politics. In: WIKIPEDIA: the free encyclopedia. [San Francisco, CA: Wikimedia Foundation, 20--]. Disponível em: https://en.wikipedia.org/ wiki/Dog-whistle_politics. Acesso em: 20 nov. 2019. artigo provocativo, $\mathrm{Eco}^{35}$ desenvolve a ideia de McLuhan segundo a qual os meios assumem o controle do processo produtivo da informação e, por conseguinte, do poder - o que esperamos ter abordado de modo satisfatório na primeira parte do artigo. A argúcia de Eco nos obriga a acompanhar seu pensamento com mais vagar.

Ao redefinir o código a partir de suas funções, Eco afirma: "um código é um sistema de possibilidades pré-fixadas e só com base no código estamos aptos a determinar se os elementos das mensagens são intencionais (desejados pela fonte) ou conseqüência do ruído" ${ }^{36}$. Com isso, confere aos diferentes usos do código a prerrogativa de incorporar determinado conteúdo e de ampliar o campo interpretativo de suas possibilidades, firmando assim a ideia de que "o universo das comunicações de massa está repleto dessas interpretações discordantes; diria que a variabilidade das interpretações é a lei constante das

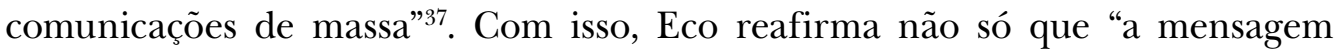
depende do código", como também que o uso dos códigos são incontroláveis e completamente imprevisíveis: "não são controláveis nem pela vontade privada, nem pela coletividade" ${ }^{38}$. Em última análise, trata-se de considerar que o uso dos códigos implica redimensionar não a codificação de partida nem a descodificação dentro do registro correspondente, mas sim a recodificação, quando o destinatário aciona as mensagens com os códigos de seu universo vivencial, de seu repertório intelectual e de sua habilidade crítica.

A internet está longe de desenvolver a habilidade intelectual apresentada por Eco, embora haja iniciativas que mereçam ser examinadas como, por exemplo, aquela proposta pela operação semiótica em voga na internet chamada de dog whistle, que é verbete na Wikipedia como Dog-whistle politics ${ }^{39}$. A operação consiste em emitir uma mensagem política que parece significar algo para a população em geral, mas que tem um significado diferente ou mais específico para um outro subgrupo, já pré-determinado nesta estratégica de comunicação. Como se sabe, os apitos de cachorro emitem frequências que os humanos não podem ouvir. $\mathrm{O}$ código recodificado agiria então como o apito que ressoa numa frequência que os humanos não conseguem ouvir, mas que os cachorros conseguem. O mesmo acontece com aquilo que é audível só pelos grupos munidos do código para decifrar o código emitido.

Diante dessa ambivalência dos códigos, que compromete a consagrada ideia de que os meios transmitem ideologia da sociedade industrial de modo unilateral, Eco propõe a necessidade de uma conduta de guerrilha semiológica que pode ser compreendida pelo raciocínio que se segue.

Se quiserem uma formulação menos paradoxal, direi: a batalha pela sobrevivência do homem como ser responsável na era da comunicação não é vencida lá onde a comunicação parte, mas aonde ela chega. Se falei em guerrilha é porque nos espera um destino paradoxal e difícil - digo a nós, cientistas da comunicação e técnicos da comunicação: justamente enquanto os sistemas de comunicação prevêem uma só fonte industrializada e uma só mensagem que chegará a um público disperso no mundo inteiro, nós teremos que ser capazes de imaginar sistemas de comunicação complementar que nos permitam atingir cada grupo humano 
isolado, cada membro isolado do público universal, para discutir a mensagem que chega à luz dos códigos de chegada, confrontando-os com os de partida ${ }^{40}$.

Formulações como essas marcaram as grandes querelas teóricas dos estudos de comunicação ao longo da segunda metade do século XX e assim permaneceram. Pouca ou quase nenhuma atenção lhes foi dedicada pelos estudiosos dos meios uma vez que o código, na episteme comunicacional dos meios de massa, foi considerado um sistema de informação fechado, restrito a sua unicidade. $\mathrm{O}$ entendimento do código único da língua como um processo naturalizado, por exemplo, marcou apenas o início de um grande desentendimento. Enveredar por esse caminho é tarefa inglória, logo, mudar o rumo da abordagem sem fugir do problema pode representar um ganho de conhecimento. Parece ter sido esta a opção de Stuart Hall ao encaminhar estudos sobre mediações culturais - também, tal como Eco, a partir de estudos da televisão - voltadas para o circuito da codificação e decodificação, avançando assim a proposta de Eco de estudar os "códigos de chegada" como estratégia de luta pela sobrevivência na era da comunicação.

O diálogo com Hall parte de uma noção que nos é muito cara: a importância da leitura dos códigos culturais nos contextos das interações situadas no interior da ecologia semiótica da comunicação e das práticas que as relações políticas transformam em discursos. É pela leitura que a trama de tais interações enreda seus desafios. Quem fala em leitura fala, portanto, de produção discursiva de linguagem, de esferas de refrações sígnicas e de complexidades.

Para Hall, produção discursiva delimita um tipo de produção singular e distintiva entre as produções de nossa sociedade, visto que o discurso é produção sígnica codificada. Considerando que a decodificação discursiva só se efetiva quando da circulação social, aquilo que foi codificado entra na dinâmica da interação e se transforma no movimento de sua enunciação ${ }^{41}$. Assim, "no momento em que um evento histórico é posto sob o signo do discurso, ele é sujeito a toda a com-

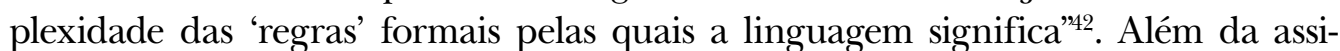
metria entre momento de codificação e de decodificação, a distinção entre códigos da fonte e códigos de recepção evidencia as ações que tanto transmitem quanto distorcem o que foi codificado, denunciando os ruídos potenciais do processo de circulação e de decodificação ou, como afirma Hall ${ }^{43}$, "o que são chamadas de 'distorções' ou 'mal-entendidos' surgem precisamente pela falta de equivalência entre os dois lados na troca comunicativa”. Eis uma lição educacional de leitura dos meios de comunicação legado pelos estudos de televisão, que merecem ser reposicionados com relação aos meios digitais que operam uma diversidade de códigos, particularmente porque eles se organizam a partir do que $\mathrm{Hall}^{44}$ define como "paradigma semiótico" configurado pelos signos icônicos ${ }^{45}$.

A complexidade que nos afronta advém da dominante discursiva produzida pelos signos icônicos, aqueles que traduzem o mundo tridimensional em signos bidimensionais (como as formas audiovisuais) ou numéricos (como as formas digitais). Refrações que não escapam nem mesmo aos códigos que parecem naturalizados, tamanha é a similaridade produzida entre as condições perceptivas
40. ECO, op. cit., p. 173

41. HALL, Stuart. Codificação/decodificação. In HALL, Stuart; SOVIK, Liv (org.). Da diáspora: identidades e mediações culturais. Belo Horizonte: Editora UFMG, 2006. p. 365-381. Ver também FAUSTO NETO, Antônio. Enunciação, auto-referencialidade e incompletude. Revista FAMECOS, Porto Alegre, v. 14, n. 34, p. 78-85, 2007.

42. HALL, op. cit., p. 366 .

43. Ibidem, p. 369.

44. Ibidem, p. 370.

45. Sob a denomi. nação de ícone, o estudo semiótico entende a construção sígnica orientada pelos processos de similaridade entre instâncias que naturalmente não apresentam nenhuma conexão ou correspondência, uma vez que resultam da mediação de códigos convencionalizados para representar o que se afirma. Lembremos aqui do consagrado estudo de Michel Foucault sobre a tela de René Magritte, La trahison des images (A traição das imagens), em que a frase aposta à tela "Ceci n'est pas une pipe" (Isto não é um cachimbo)-é examinada como paradoxo e autorreferencialidade. $O$ ícone afirma que se trata de um desenho de um cachimbo, não equivalente ao cachimbo do mundo empírico, enquanto a percepção do espectador the diz o contrário, ainda que ele saiba que o desenho não se presta à degustação de quem fuma. FOUCAỦLT Michel. Isto não é um cachimbo. Rio de Janeiro: Paz e Terra, 1988. 
de quem entra em contato com eles. Contudo, como entendeu Hall, "essas condições de percepção são o resultado de um conjunto de operações altamente codificadas, ainda que virtualmente inconscientes - são decodificações"46 ${ }^{\text {. }}$

Ao examinar a construção icônica da tridimensionalidade pelas imagens audiovisuais, Hall produziu seu alerta:

Uma vez que o discurso visual traduz um mundo tridimensional em planos bidimensionais, ele não pode, é claro, ser o referente ou o conceito que significa. $\mathrm{O}$ cão, no filme, pode latir, mas não pode morder! A realidade existe fora da linguagem, mas é constantemente mediada pela linguagem ou através dela: e o que nós podemos saber e dizer tem de ser produzido no discurso e através dele. O "conhecimento" discursivo é o produto não da transparente representação do "real" na linguagem, mas da articulação da linguagem em condições e relações reais. Assim, não há discurso inteligível sem a operação de um código. Os signos icônicos são, portanto, signos codificados também - mesmo que aqui os códigos trabalhem de forma diferente daquela de outros signos. Não há grau zero em linguagem ${ }^{47}$.

A grave distorção promovida pelo desconhecimento da dialética que os signos icônicos representam se encarrega de simplificar a decodificação, ignorando a convencionalidade dos códigos que surgem, assim, naturalizados como se fossem instâncias transparentes de universos referenciais da realidade. $O$ alerta de Hall merece ser aprendido:

A operação de códigos naturalizados revela não a transparência e "naturalidade" da linguagem, mas a profundidade, o caráter habitual e a quase-universalidade dos códigos em uso. Eles produzem reconhecimento aparentemente "naturais". Isso produz o efeito (ideológico) de encobrir as práticas de codificação presentes. Mas não devemos deixar que as aparências nos enganem. Na verdade, o que os códigos naturalizados demonstram é o grau de familiaridade que se produz quando há um alinhamento fundamental e uma reciprocidade - a consecução de uma equivalência - entre os lados codificador e decodificador de uma troca de significados ${ }^{48}$.

Para o arremate de seu argumento, Hall convoca Eco, para quem os signos icônicos "parecem com objetos do mundo real porque reproduzem as condições perceptivas (ou seja, os códigos) de quem os vê" ${ }^{49}$.

Se é na instância do signo que as distorções acontecem, podemos reformular algumas questões postas inicialmente. A primeira diz respeito ao poder dos códigos e ao controle que, em seu nome, é exercido por forças hegemônicas. Se a capacidade de leitura é, de fato, uma força de intervenção transformadora, o mesmo dispositivo da inteligência humana que constrói códigos pode quebrá-lo. Não foi esta a missão de Alan Turing em favor das tropas aliadas no final da segunda guerra mundial? Pesadas as distâncias históricas, o mapa das hegemonias geopolíticas do contexto contemporâneo demanda intervenções semelhantes (não equivalentes). Contudo, faltam investimentos para que pessoas deixem de ser apenas usuários para se tornarem cidadãos conscientes dos desafios a serem vencidos. Para a manutenção de um modelo econômico baseado no consumo nos ambientes digitais, este desafio literalmente não faz sentido. Portanto, este só pode ser empreendido a partir da educação para a comunicação. O domínio dos 
códigos é apenas o início de um longo processo cujo caminho é refeito a cada novo lance de dados da imprevisibilidade cultural. Se antepassados apostaram na educação do homem-leitor, por que nós vamos desistir?

\section{CONSIDERAÇÕES FINAIS}

A superação da ignorância em relação aos meios informático-digitais da tecnocultura não pode prescindir de um projeto alfabetizador cuja iniciação não difere do aprendizado adquirido com os outros códigos. $\mathrm{O}$ aprendizado da escrita alfabética nos dotou de habilidades perceptuais e cognitivas para desenvolver outros códigos e outras habilidades. Agora, estamos em uma outra etapa de alfabetização que, a exemplo da metáfora da cebola, implica a adoção de uma educação que contemple as diversas camadas que compõem os meios informático-digitais e suas dinâmicas, como demonstrado no Quadro 1.

Os meios técnicos não são apenas fruto da racionalidade técnica. $\mathrm{O}$ valor cultural de cada um deles vincula-se ao patrimônio legado pela ecologia semiótica formado pela diversidade de códigos culturais. Exercitamos a caligrafia para o desenvolvimento da escrita verbal; aprendemos o funcionamento da câmera para aprender a escrever com luz dos códigos fotográficos e cinematográficos; e assim também há que se desenvolver e implementar projetos de alfabetização com os códigos informático-digitais, tarefa que envolve o concurso das linguagens da comunicação (verbais, visuais, sonoras, audiovisuais) e da programação no núcleo duro de suas atividades. Evidentemente que o fruto desse conjunto de escritas se traduz em domínio dos signos icônicos em sua geração pelos códigos informático-digitais.

Domínio das linguagens icônicas implica ganhos de conhecimento e ampliação de repertório que dignificam a sociedade humana com suas próprias conquistas, inventos, criações. Tal é o domínio da autorreferencialidade que nos compete conhecer, praticar, compartilhar e multiplicar, de modo a extinguir a ignorância da raiz, que insiste em nos converter em usuários de bens materiais que em nada contribuem para dignificar a existência humana no planeta. Não se trata de negar o uso que fazemos da técnica e da tecnologia, mas da educação para sua utilização a partir de competências semióticas que envolvem o aprendizado dos códigos em jogo, como discutimos previamente, e também a educação para as qualidades humanas de reflexão, o que demanda tempo para o desenvolvimento do pensamento. Caso contrário, nosso pensamento se converterá apenas em cálculo, como adverte o filósofo da comunicação Byung-Chul $\mathrm{Han}^{50}$ nos seus recentes trabalhos sobre a adoção da lógica que expomos como lógicas de vida para a humanidade.

\section{REFERÊNCIAS BIBLIOGRÁFICAS}

BENJAMIN, Walter. A obra de arte na era de sua reprodutibilidade técnica. In: BENAJMIN, Walter. Sobre arte, técnica e política. Lisboa: Relógio D’Água, 1992. p. 71113.
50. HAN, Byung-Chul. Sociedade da transparência. Petrópolis: Vozes, 2017a; Idem. Sociedade do cansaço. Petrópolis: Vozes, 2017b; Idem. Topologia da violência. Petrópolis: Vozes, 2017c. 
comunicação \& educação • Ano XXIV • número 2 • jul/dez 2019

CAMPOS, Augusto de. Paul Valéry: a serpente e o pensar. São Paulo: Brasiliense, 1984.

BETTETINI, Gianfranco. Las ambigüedades del sujeto informador. BETTETINI, Gianfranco. La conversación audiovisual. Madrid: Cátedra, 1996. p. 63-70.

COLOMBO, Fausto. El ícono ético: la imagen de síntesis y un nuevo paradigma moral. In: TALENS, Jenaro (dir.). Videoculturas de fin de siglo. Madrid: Cátedra, 1990. p. 145156.

DOG-whistle politics. In: WIKIPEDIA: the free encyclopedia. [San Francisco, CA: Wikimedia Foundation, 20-]. Disponível em: https://en.wikipedia.org/ wiki/Dog-whistle_politics. Acesso em: 20 nov. 2019.

ECO, Umberto. Guerrilha semiológica. In: ECO, Umberto. Viagem na irrealidade cotidiana. Rio de Janeiro: Nova Fronteira, 1984. p. 65-75.

ENGELS, Friedrich. Humanização do macaco pelo trabalho. In: ENGELS, Friedrich. A dialética da natureza. Rio de Janeiro: Paz e Terra, 1979.

FAUSTO NETO, Antônio. Enunciação, auto-referencialidade e incompletude. Revista FAMECOS, Porto Alegre, v. 14, n. 34, p. 78-85, 2007.

FOUCAULT, Michel. Isto não é um cachimbo. Rio de Janeiro: Paz e Terra, 1988.

FOUCAULT, Michel. Nascimento da biopolítica. Lisboa: Edições 70, 2010.

GALLOWAY, Alexander. Protocol: how control exists after decentralization. Massachusetts: The MIT Press, 2004.

HALL, Stuart. Codificação/decodificação. In: HALL, Stuart; SOVIK, Liv (org.). Da diáspora: identidades e mediações culturais. Belo Horizonte: Editora UFMG, 2006. p. 365-381.

HAN, Byung-Chul. Sociedade da transparência. Petrópolis: Vozes, 2017a.

HAN, Byung-Chul. Sociedade do cansaço. Petrópolis: Vozes, 2017 b.

HAN, Byung-Chul. Topologia da violência. Petrópolis: Vozes, 2017c.

HERN, Alex. Revealed: how TikTok censors videos that do not please Beijing. The Guardian, London, 25 set. 2019. Disponível em: https://www. theguardian.com/technology/2019/sep/25/revealed-how-tiktok-censorsvideos-that-do-not-please-beijing. Acesso em: 14 out. 2019.

HISTORY. In: TOR Project. Seattle: The Tor Project, 2011. Disponível em: https://www.torproject.org/about/history/. Acesso em: 27 dez. 2019.

HOFSTADTER, Douglas. Godel, Escher, Bach: an eternal golden braid. New York: Basic Books, 1979. 
JAKOBSON, Roman. Linguística e poética. In: JAKOBSON, Roman. Linguística e comunicação. São Paulo: Cultrix, 1971. p. 118-162.

LINGUAGEM assembly. In: WIKIPÉDIA: a enciclopédia livre. [San Francisco, CA: Wikimedia Foundation, 2016]. Disponível em: http:/ /pt.wikipedia.org/ wiki/Assembly. Acesso em: 25 out. 2010.

LOTMAN, Iuri. A estrutura do texto artístico. Lisboa: Estampa, 1978.

LOTMAN, Juri. The unpredictable workings of culture. Tallinn: Tallinn University Press, 2013.

MANOVICH, Lev. Database as symbolic form. Convergence, Thousand Oaks, v. 5, n. 2, p. 81-99, 1999. Disponível em: http://con.sagepub.com/ content/5/2/80. Acesso em: 5 maio 2019.

MATURANA, Humberto. Emociones y lenguaje en educación y política. Santiago: Dolmen, 1997.

MATURANA, Humberto; VARELA, Francisco. A árvore do conhecimento: as bases biológicas do entendimento humano. Campinas: Psy, 1995.

MCLUHAN, Marshall; FIORE, Quentin. O meio são as massagens: um inventário de efeitos. Rio de Janeiro: Record, 1969.

MORIN, Edgar. O ano zero da Alemanha. Porto Alegre: Sulina, 2009.

PÉREZ, Ignacio. El rol de los proxies y protocolos en la investigación de malware. We live security, Buenos Aires, 29 maio 2015. Disponível em: https://www.welivesecurity.com/la-es/2015/05/29/proxies-y-protocolosinvestigacion-malware/. Acesso em: 15 nov. 2019.

PRIGOGINE, Ilya; STENGERS, Isabelle. A nova aliança. 3. ed. Brasília, DF: Editora UnB, 1997.

SHIRKY, Clay. Lá vem todo mundo: o poder de organizar sem organizações. Rio de Janeiro: Zahar, 2011.

THACKER, Eugene. Foreword: protocol is as protocol does. In: GALLOWAY, Alexander. Protocol: how control exists after decentralization. Massachusetts: The MIT Press, 2004. p. XI XXIV.

TIM Berners-Lee. In: WIKIPÉDIA: a enciclopédia livre. [San Francisco, CA: Wikimedia Foundation, 20-]. Disponível em: https://pt.wikipedia.org/wiki/ Tim_Berners-Lee. Acesso em: 20 nov. 2019.

VOLLI, Ugo. Factoides y mnemos: por una ecología semiótica. In: TALENS, Jenaro (dir.). Videoculturas de fin de siglo. Madrid: Cátedra, 1990. p. 129-135.

WIENER, Anna. The complicated legacy of Stewart Brand's "Whole Earth Catalog". The New Yorker, New York, 16 nov. 2018. Letter from Silicon Valley. Disponível em: https://wwuw.newyorker.com/news/letter-from-siliconvalley/the-complicated-legacy-of-stewart-brands-whole-earth-catalog. Acesso em: 15 nov. 2019. 